\title{
APROXIMACIÓN FACIAL EN EL ÁMBITO DE LA ARQUEOLOGÍA: CASO PRÁCTICO DE UN INDIVIDUO DEL YACIMIENTO DE ELS ALTIMIRIS (PREPIRINEO CATALÁN)
}

\section{FACIAL APPROACH IN THE FIELD OF ARCHEOLOGY: CASE STUDY OF AN INDIVIDUAL OF THE ELS ALTIMIRIS DEPOSIT (CATALAN PRE-PYRENEES)}

\author{
Marta Medina Palau \\ (Laboratorio de Arqueología Medieval de la Universidad de Barcelona, España) \\ 10martamedina@gmail.com
}

Recibido el 06 de septiembre de 2017; aceptado el 20 de noviembre de 2017

\begin{abstract}
RESUMEN: El presente trabajo versa sobre un caso de aplicación de las aproximaciones faciales en 3D en un individuo adulto procedente del yacimiento de Els Altimiris (Sant Esteve de la Sarga, Catalunya), con el fin de determinar qué características y rasgos faciales presentaba la sociedad de esta zona en la Edad Media, además de demostrar la potencialidad de dicha tecnología. Se propone una primera aproximación a la arqueología virtual focalizada en el patrimonio antropológico, mediante una serie de técnicas y programas de diseño 3D que permitirán recrear el rostro del individuo estudiado de forma realista.
\end{abstract}

PALABRAS CLAVE: Aproximación facial, arqueología medieval, antropología, virtualización, patrimonio.

\begin{abstract}
The aim of this paper is to elaborate a facial approximation in 3D of an adult from the Els Altimiris archaeological site (Sant Esteve de la Sarga, Catalunya), in order to determine which characteristics and facial features presented the society from this area in the Early Middle Ages, as well as demonstrate the potentiality of this technology. A first approximation in virtual archaeology focused in anthropological heritage is presented, by various techniques and $3 \mathrm{D}$ design software, which will allow us to recreate the face of the individual studied in a realistic way.
\end{abstract}


KEYWORDS: facial approximation, medieval archaeology, anthropology, virtualization, heritage.

\section{APROXIMACIÓN FACIAL DE UN INDIVIDUO DEL PREPIRINEO CATALÁN: EL CASO DE ELS ALTIMIRIS}

La reconstrucción facial es el arte científico de construir un rostro sobre un cráneo con el propósito de identificar a un individuo Wilkinson (2004, p. 39)

Uno de los campos de la arqueología virtual que más se está popularizando en los últimos años es el de las aproximaciones o reconstrucciones faciales 1 . Se trata de una disciplina poco explorada -a nivel de diseño 3D por ordenador- debido a la alta precisión y realismo que requiere. Hasta hace poco era muy difícil conseguir retratos objetivos mediante un software de diseño tridimensional. La evolución de los programas informáticos ha facilitado que actualmente sea posible realizar aproximaciones faciales en 3D con mayor realismo.

Hoy en día, las nuevas tecnologías forman parte de nuestra vida y son grandes herramientas para mejorar estudios en el campo de la arqueología y la antropología física. Las reconstrucciones faciales se pueden realizar a partir de tres técnicas principales: la representación en 2D (dibujar sobre la fotografía de un cráneo), la reconstrucción en 3D (utilizar técnicas de modelaje) y la reconstrucción en 3D digital.

Sin embargo, aunque actualmente es muy común la creación de aproximaciones faciales de forma digital por ordenador en el área forense, es importante remarcar que el proceso siempre es manual y, por lo tanto, la aproximación no se obtiene de forma automatizada, sino que requiere de una alta profesionalización.

En este caso de estudio se ha elegido la técnica de la reconstrucción facial en 3D digital con programas de libre acceso (PhotoScan y Blender) y se han seguido los métodos

\footnotetext{
1 Una aproximación o reconstrucción facial, según el profesor Pablo Aparicio (a quién agradecemos sus amables comentarios) de las Universidades de Alicante y Burgos, es un dibujo o una escultura (analógica o digital) creada a partir de un cráneo humano sin identificar. Su aplicación tiene como principal objetivo dar a conocer un individuo a través de su cráneo. Es una técnica que se utiliza con frecuencia en el arte forense para cuestiones criminológicas, pero también se usa, y cada vez más, en el área de la investigación y difusión del patrimonio.
} 
más convenientes según facilidad y disponibilidad: la previa documentación antropológica y arqueológica (ya que proporcionan detalles que no se pueden conocer únicamente a partir del cráneo), la fotogrametría del cráneo (para adquirir un modelo tridimensional) y el modelaje digital (para la creación de la piel, detalles y texturas).

El individuo objeto de este estudio es uno de los dos esqueletos que se encontraron en el yacimiento arqueológico de Els Altimiris. Este es un asentamiento que se origina en el siglo $\mathrm{V}$ y se abandona en el siglo IX, con un momento álgido entre los siglos VI y VII y frecuentaciones esporádicas posteriores (Sancho, 2011: 11). Se interpreta como un conjunto eclesiástico eremítico-cenobítico (Sancho, 2010: 83) ubicado en la cima de la Sierra del Montsec donde solamente se han documentado dos individuos. Es por este motivo que resulta tan interesante disponer de la reconstrucción facial de uno de los habitantes de esa zona, ya que puede proporcionar más información de cómo era la sociedad del Prepirineo en la Edad Media.

Respecto al estudio antropológicor del individuo, se trata de un adulto masculino de entre 40 y 60 años. Presenta una serie de patologías como caries, artrosis, cavidades infecciosas bucales, etc., pero una de las más importantes que se observa es un traumatismo en el fémur derecho que llegó a soldarse antemortem. A nivel morfológico, el conjunto de las características del esqueleto determina que se trata de un individuo masculino robusto y se ha calculado que mediría entre 165 y $168 \mathrm{~cm}$. Los resultados de los análisis de datación por radiocarbono fechan el individuo en la segunda mitad del siglo XI. El cráneo es redondeado, las órbitas de medida mediana, el agujero óseo de la nariz estrecho y la mandíbula sobresale a causa de una infección bucal [1]. Todas estas patologías repercutirán en el resultado final de la reconstrucción facial.

\footnotetext{
2 AGUSTÍ, B. Altimiris-2008. Estudi antropològic. Barcelona. Trabajo inédito.
} 


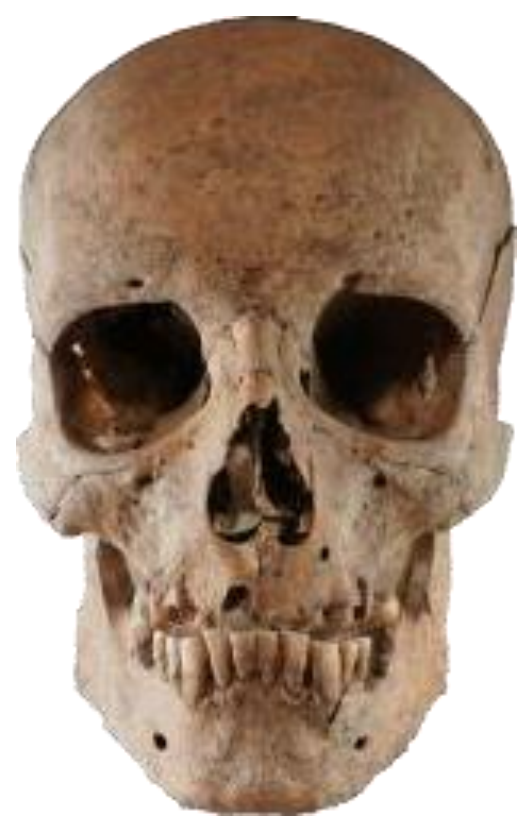

[1] Cráneo arqueológico del individuo adulto de Els Altimiris. [Fotografía de Marta Medina]. (Laboratori d'Arqueologia Medieval, 2016). Universidad de Barcelona.

Una vez realizado el estudio antropológico, se realiza el modelo tridimensional del cráneo a partir de la fotogrametría. La fotogrametría es una técnica que será la base para conseguir la aproximación facial. Consiste en capturar imágenes de forma consecutiva siguiendo una misma dirección. Estas imágenes se solapan entre ellas, para que después, al ser procesadas con un software fotogramétrico, se obtenga un modelo 3D de alta precisión (Moraes, Miamoto, 2015: 54).

El último paso consiste en crear la musculatura, la piel, detalles y texturas con un software de modelaje digital. Esta última fase se puede dividir en seis partes esenciales. La primera consiste en la colocación de los marcadores de espesor facial (Soft Tissue Depth Markers) en determinados puntos del cráneo. Estos marcadores de morfología cilíndrica sirven para establecer el grosor del tejido blando de cada parte de nuestro rostro. Según el sexo, edad, peso y raza, el grosor de estos puntos variará ligeramente. Existen tablas diversas, con más o menos puntos cráneo-faciales, pero en este caso de estudio se ha decidido situar 25 marcadores siguiendo la tabla de valores del Dr. Carl Stephan ya que se actualiza anualmente3[2].

\footnotetext{
3 www.craniofacialidentification.com/TFSTDD.html [2017/03/16]
} 


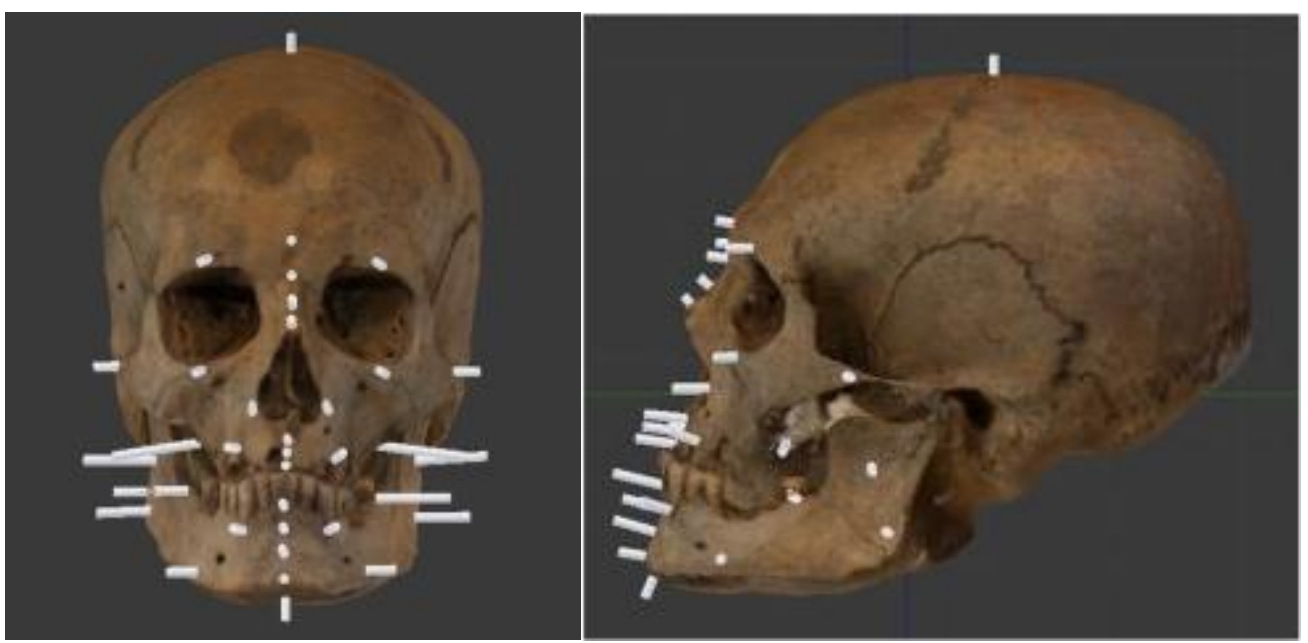

[2] Vista frontal y lateral del cráneo con los marcadores de espesor facial. [Fotografía de Marta Medina]. (2017).

La segunda parte se basa en la conversión de las medidas obtenidas mediante fotogrametría a escala real. Este es un problema muy frecuente y es imprescindible trabajar con las mismas unidades y con medidas reales. Hay que tener en cuenta que es vital que el cráneo digital esté escalado, ya que sino no se podrá trabajar con los marcadores de espesor facial. En el caso del adulto estudiado, las unidades no eran las correctas, sino que había una mezcla entre metros y centímetros, y las medidas tampoco concordaban con las reales. Así que fue necesario unificar las unidades a centímetros y convertir las medidas para que se adecuaran a las reales. En cuanto se consigue que las medidas sean fiables y reales, cualquier estudio que se quiera realizar de este cráneo será correcto. Es en este punto cuando se colocan los marcadores de espesor facial.

La tercera parte del proceso, previa a la creación de la musculatura, consiste en dibujar la silueta del rostro del individuo y posicionar los ojos. Esta parte permite visualizar cómo será la cara y así facilitar el siguiente proceso. La obtención del contorno de la cara no es subjetiva, sino que sigue unos patrones científicos mediante los marcadores de espesor facial. Se trata de reseguir el contorno del cráneo uniendo todos los marcadores. En las partes del tejido blando donde no hay marcadores como la nariz, orejas y labios, es donde el autor de la reconstrucción, en el proceso de modelaje de los músculos, debe escoger el método que más le convenga seguir. Respecto a los ojos, es muy importante elegir el color correcto del iris porque es uno de los 
marcadores que permite identificar a un individuo. Como el caso estudiado se trata de un individuo de origen arqueológico, es muy difícil y prácticamente imposible de identificar. A pesar de ello, se opta por un color marrón avellana ya que es el color más probable y adecuado para los individuos mediterráneos según señalan los estudios de tipo morfo antropológico.

En el punto de la creación de la musculatura, para evitar cualquier interpretación artística, se deben seguir las directrices anatómicas de la musculatura. Para conseguirlo se suelen utilizar atlas de anatomía e imágenes de referencia. Hay que tener en cuenta que en esta parte de la aproximación es donde se cometen más errores. Se trata de modelar los músculos a partir de polígonos e ir esculpiéndolos digitalmente añadiendo detalles y color para crear una textura similar a la muscular. Para posicionar correctamente los músculos, se tienen que dejar unos $2 \mathrm{~mm}$. de distancia en los marcadores de espesor facial ya que posteriormente se colocará la capa de la piel [3].

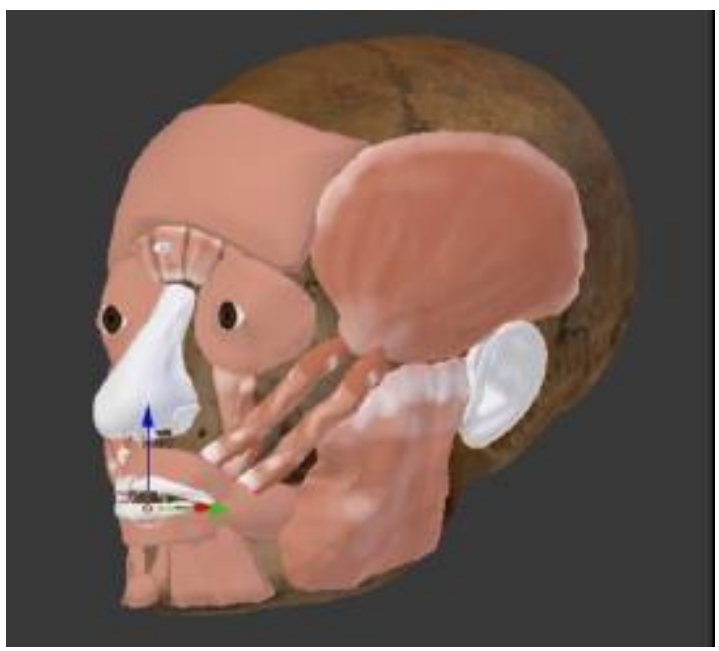

[3] Cráneo con musculatura. [Fotografía de Marta Medina]. (2017).

Tres elementos que deben ser reconstruidos de forma diferente son la nariz, las orejas y los labios porque son más blandos que los demás y presentan un grado de variación mucho más alto según cada individuo. De estos tres, la nariz es la única que se puede predecir con cálculos matemáticos. Los labios y las orejas son totalmente de creación artística, teniendo estas últimas generalmente un ángulo de inclinación de $15^{\circ}$ hacia atrás (Taylor, 2001: 448) siguiendo la dirección de la mandíbula. Una vez se han modelado todos los músculos, se lleva a cabo la restitución de la piel. La piel se modela poco a poco adaptándola a los marcadores de espesor facial hasta que queden todos cubiertos. En el caso del cráneo de Els Altimiris, la 
piel adopta una forma característica porque algunos marcadores como son los de los labios y los de la nariz otorgan al individuo una forma robusta y corpulenta [4]. Este resultado es el adecuado, ya que, según el estudio antropológico del esqueleto, este individuo presenta un conjunto de características muy robustas.

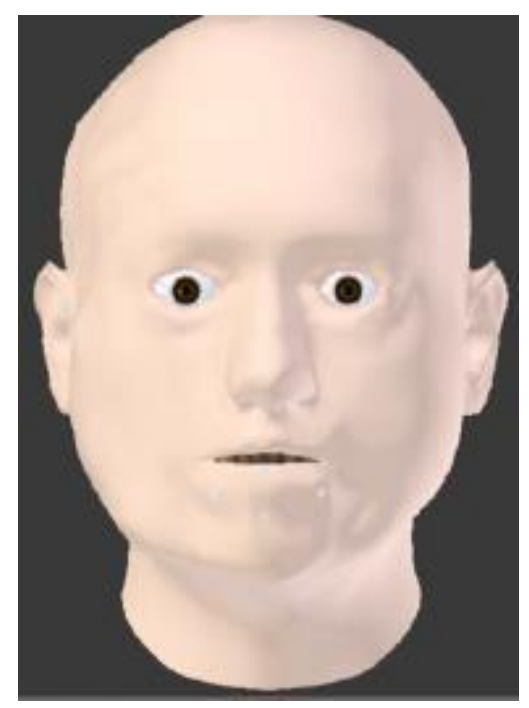

[4] Cráneo con capa de piel. [Fotografía de Marta Medina]. (2017)

La sexta y última parte del modelaje digital es la creación de los detalles, texturas y pelo. Primero, se le proporciona a la piel color y brillo. Este paso es totalmente artístico y a elección de la persona que realiza la aproximación facial. Carece de rigor científico porque se trata de un sujeto arqueológico y no se pueden extrapolar pobladores con afinidad biológica cercana a la zona de Els Altimiris como sí se hace en casos forenses actualmente. Solamente se puede conocer el color real de los ojos, del pelo, etc., si se realizan análisis de ADN. Como el individuo estudiado se localizó en una zona de alta montaña y tiene una edad media de 50 años, se ha optado por el color de piel morena, característica de las poblaciones mediterráneas.

Con las herramientas de esculpido digital de los programas informáticos se da textura al modelo a base de crear detalles como poros, arrugas, etc., para que tenga una apariencia similar a la piel. En algunas zonas hace falta añadir detalles más marcados que en otras. Por ejemplo, en el cráneo de Els Altimiris se ha insistido en añadir elementos indicadores de vejez sobre todo en la zona de los ojos, nariz, mejillas y boca, ya que el individuo se encontraba en una edad avanzada para la época y es probable que tuviera bastantes arrugas. Todos estos detalles de texturización proporcionarán un acabado meticuloso y realista al modelo 
definitivo.

Con referencia al cabello, es de creación artística como la piel. En el caso del cráneo de Els Altimiris, aunque no se dispone de una base científica, se ha decidido confeccionar los cabellos a partir de la documentación gráfica como es la iconografía. Se han utilizado los beatos como fuente iconográfica, concretamente en este caso el Beatus de la Seu d'Urgell, el más próximo a la zona de Els Altimiris y de una cronología cercana a la del individuo estudiado. Prácticamente solo aparecen hombres adultos con cabellos largos hasta las espaldas, ondulados y lisos, y de coloración oscura (desde tonalidades marrones a negros). La barba es un elemento opcional. Puede hacer variar la identificación de una persona. En este caso de estudio, aunque en el Beatus de la Seu d'Urgell no aparece ningún hombre con barba, se ha considerado adecuado incorporar una al individuo de Els Altimiris, una barba semiespesa de coloración marrón oscuro con algunas canas que empezarían a surgir, ya que es un elemento más de vejez y madurez. Por lo que respecta al Beatus de la Seu d’Urgell, aparecen personajes idealizados, jóvenes y con la misma fisonomía. Este es otro motivo por el que se ha elegido incorporar una barba ya que dota la cara de más realismo [5].

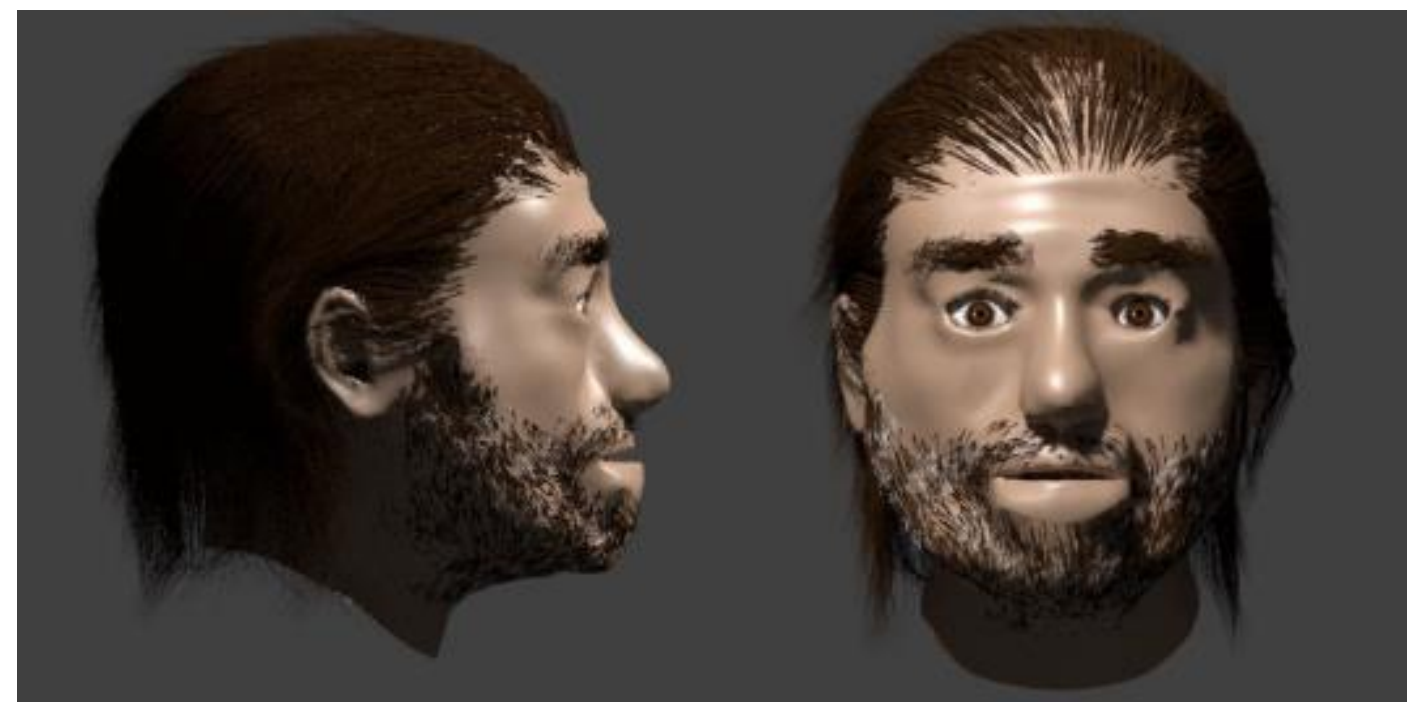

[Fig. 5] Resultado final de la reconstrucción facial. [Fotografía de Marta Medina]. (2017) 
Es una tarea compleja reproducir un rostro a partir de un cráneo arqueológico. A pesar de ello, se ha podido reconstruir el rostro de este habitante del siglo XI de Els Altimiris. De todas maneras, esta aproximación facial presenta mucho más potencial del que se ha podido realizar. Por tanto, es posible profundizar más en ciertas cuestiones que pueden mejorar como el aspecto final de la piel, ya que con otros programas se podría conseguir una textura menos plástica y más porosa. Además, esta reconstrucción facial es un primer ejemplo de iniciación en las técnicas virtuales, así que cuanta más experiencia y especialización se tenga en este campo, mejores serán las reconstrucciones.

Aunque se ha podido obtener uno de los rostros de la población medieval del Prepirineo catalán, hay que tener en cuenta que no se puede considerar representativo de toda esta sociedad ya que solo se ha estudiado un caso. Para ser representativo deberíamos realizar reconstrucciones faciales de individuos de otros yacimientos del mismo territorio y comparar resultados. No obstante, este primer ejemplo proporciona una visión general de lo que serían los rasgos característicos propios de los individuos masculinos de la zona: robustez de las facciones y nariz predominante. Estas características permiten observar la evolución y adaptación al medio de los habitantes de esa área a lo largo del tiempo.

Este caso de estudio también ilustra la necesidad de pluridisciplinariedad, ya que además de utilizar el diseño virtual aplicado a la Arqueología, también se ha precisado de técnicas artísticas, estudios antropológicos y fórmulas matemáticas para poder realizarlo. Por tanto, en el mundo de la arqueología el trabajo en equipo es esencial y este concepto se materializa en forma de colaboración con otros profesionales. En un primer momento, parece que la disciplina de recreación virtual sea muy individual, no obstante, es vital intercambiar datos con otros expertos y discutir técnicas y métodos de trabajo. De esta manera, se obtiene una mejora del proceso de creación y de los resultados del 3D.

Las reconstrucciones faciales virtuales son una gran herramienta para el análisis y la difusión del Patrimonio Cultural e Histórico. A través de estas podemos comprender mejor la sociedad ya que al relacionar el individuo con su imagen, el público se ve reflejado, por lo que consiguen generar curiosidad y empatía.

Uno de los puntos más interesantes de esta reconstrucción facial, aparte de ser la 
primera que se ha realizado en todo el territorio del Prepirineo, es el hecho de que no corresponde a un personaje histórico, sino a un habitante desconocido. La reconstrucción de su rostro proporciona más información al público sobre su persona, permite comprender la sociedad medieval del Prepirieno catalán y ayuda a detectar similitudes entre la sociedad actual de la zona.

Respecto a la fiabilidad de la metodología efectuada, no es del todo exacta porque no se dispone de una fotografía o imagen para hacer comparaciones. Algunas partes concretas como las orejas, el color del cabello y ojos, labios, etc. no se han podido reconstruir fielmente porque son partes blandas que no se han conservado; por tanto, son estimaciones. Aun así, siguiendo las directrices de autores expertos en la materia como Caroline Wilkinson, se ha conseguido desarrollar una metodología efectiva para obtener un resultado suficientemente preciso. Actualmente, según las opiniones de los expertos, la técnica de la reconstrucción facial en 3D tiene un $80 \%$ de fiabilidad.

\section{REFERENCIAS BIBLIOGRÁFICAS}

AGUSTÍ, Bibiana (2009), “Altimiris 2008 - Estudi antropològic”. Barcelona. Trabajo inédito. MORAES, Cicero, MIAMOTO, Paulo (2015), "Manual de Reconstruçao Facial 3D Digital". Recuperado de:

http://www.ciceromoraes.com.br/ebook/pdf/MANUAL\%20DE\%20RECONSTRU\%C3\%87 \%C3\%8 30\%20FACIAL\%203D\%20DIGITAL.pdf (fecha de consulta: 20-03-2017).

SANCHO, M. (2010). "Els Altimiris.”. Histoire et Archéologie des Sociétés de la Vallée de l’Èbre (VIIe-XIe siècles), Toulouse, Études Médiévales Ibériques. pp. 67-90.

SANCHO, Marta (2011), "Quins cristians per a Els Altimiris? Propostes de contextualització d'un jaciment Tardoantic i Altmedieval del Prepirineu lleidatà", en Urgellia: Anuari d'estudis històrics dels antics comtats de Cerdanya, Urgell i Pallars, d'Andorra i la Vall d'Aran, nº17, pp. 801-816.

TAYLOR, Karen (2001), "Forensic Art and Illustration”, CRC Press, Boca Raton: Florida, pp. 3- 563.

WILKINSON, Caroline (2004), "Forensic Facial Reconstruction", University Press, 
Cambridge, pp. 5-284. 